\title{
Structural Size Optimization of External Fixation Device
}

\author{
Elmedin Mešić ${ }^{1}$, Adil Muminović ${ }^{1}$, Mirsad Čolić ${ }^{1}$, Marin Petrović ${ }^{1}$, Nedim Pervan ${ }^{1 *}$ \\ 1 University of Sarajevo, Mechanical Engineering Faculty Sarajevo, Vilsonovo šetalište 9,Sarajevo, Bosnia and \\ Herzegovina \\ * Corresponding author's e-mail: pervan@mef.unsa.ba
}

\begin{abstract}
Structural size optimization of a device for external bone fixation within a formed iterative hybrid optimization algorithm was presented in this paper. The optimization algorithm was in interaction with the algorithms for generative design and FEM analysis and completely integrated within CATIA CAD/CAM/CAE system. The initial model, representing the current design of the bone external fixation device Sarafix, was previously verified by experimental testing. The formed hybrid optimization algorithm was created as an integration of the global (SA method) and local (CG method) algorithm. The constraints of the optimization model are the clinical limitations of the interfragmentary displacements and the material strength. The optimized design has less weight, greater rigidity and less transverse interfragmentary displacements at the point of fracture compared to the current design.
\end{abstract}

Keywords: structural size optimization, external fixation device, SA method, CG method interfragmentary displacements, principal stresses.

\section{INTRODUCTION}

The basis for the structural size optimization is a parametric description of a computer representation of a real object by a set of geometric, dimensional, physical, functional and other parameters. Size optimization is most often carried out at the stage of detailed design, i.e. when the topology and shape of the product are predefined. The term parametric design associated with parametric systems is defined as "a process of designing with parametric models in a virtual surrounding where geometrical and parameter variation are natural" $[18,21]$.

The concept of structural size optimization of an external fixation device is shown in Figure 1 [8]. This iterative optimization process begins by generating an initial parameterized CAD model based on three reference design parameters. On thus formed CAD model, the FEM model is preprocessed or developed. The structural analysis using displacement and stress sensors reads their state and introduces them into the optimization module in the form of optimization constraints.
The reference design parameter data are fed into the optimization module after each iteration from the CAD module and used as the states of the optimization parameters. In addition, the geometry data from the CAD module are used in order to calculate the construction volume and use it as a cost function in the optimization module. The actions described make a single iteration of the algorithms for generative design, FEM analysis and optimization and are repeated until one of the termination criteria is reached. The initial CAD/ FEM model is verified by experimental testing.

There is a lot of research papers about the structural optimization used in the design process. Usually it is topology optimization, or optimization of the shape and size $[3,4,5,13,14,23,24]$.

\section{Development and experimental validation of a generative CAD/FEM model}

In order to achieve the flexibility of the created CAD model, so-called Top-Down method was used. This method involves the work mode with the view from above over the basic model, as well 


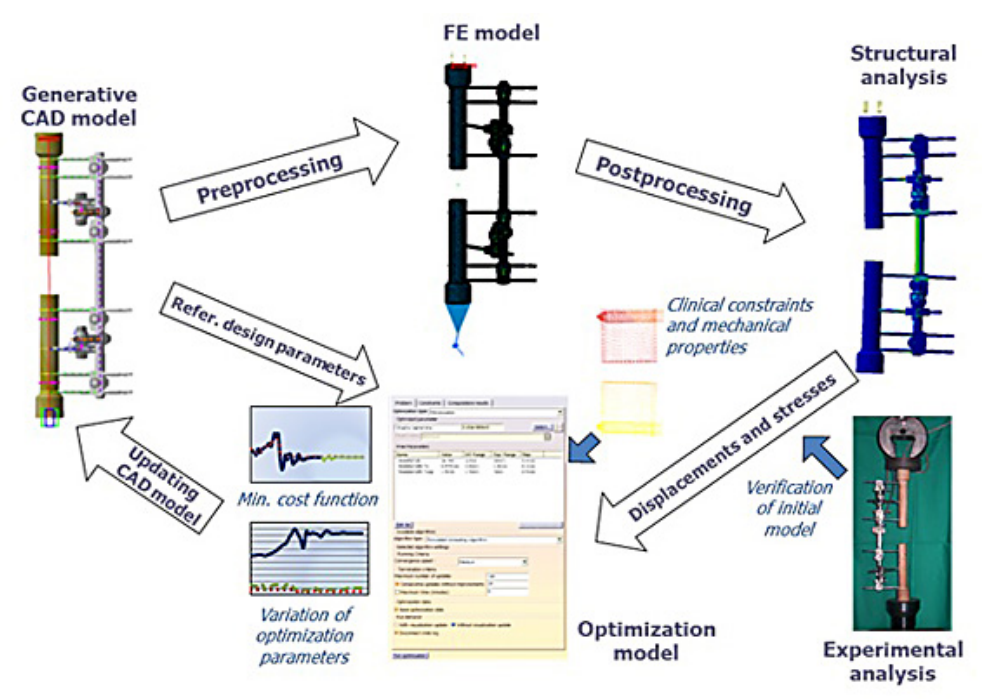

Fig. 1. Structural size optimization concept of an external bone fixation device

as applying associativity and using parameterized relations [1]. This approach is actually reflected in the formation of so-called parameterized skeleton representing the infrastructure (simplified design) of the fixator through which appropriate interactions between the design parameters are established. In this way, the design knowledge is integrated into the CAD model through the skeleton, which is the basis of the so-called generative modelling.

The external fixation device components were modelled by finite elements of linear and parabolic tetrahedron type. Both elements belong to the group of 3D isoparameter elements or solids with six edges. For approximation of geometry and the field of basic unknowns of isoparametric elements, the same interpolation functions and the same nodes are used $[19,25]$. There are three degrees of freedom in each node of these finite elements: displacements $u, v$, and $w$ in $x, y$, and $z$ axes of the rectangular coordinate system.

The external fixator is made of special stainless steel for the manufacturing of medical devices. An orthotropic material with three planes of symmetry is a special form of anisotropic material. For orthotropic material, it is common to define the material parameters such as Young's modulus of elasticity, Poisson's coefficient and shear modulus. The bone segments models were made of beech wood with known properties. Wood belongs to the group of anisotropic materials, but due to the cylindrical symmetry of its structure, it can be regarded as an orthotropic material where the properties are defined in three planes [25].
The basic load form of the external fixator is axial pressure. An appropriate FEM model was developed to simulate experimental testing on axial load, taking into account the complete geometry of the external fixation device and bone model, the connections between the components, the applied load, as well as the constraints applied $[9,15]$. When tested for axial loading, the bone models were reliant on spherical joints, while the intensity of axial loading by compression force of the proximal bone segment ranged in the interval $F_{p}=0-600 \mathrm{~N}$ with a growth rate of $5 \mathrm{~N} / \mathrm{s}$. The FEM model layout of the fixator before and after the application of the maximum axial pressure with the representation of the interfragmentary displacements is given in Figure 2.

In order to define the maximum interfragmentary displacement at the fracture point $R$, displacements in the $x, y$ and $z$ directions of a pair of adjacent points at the end planes of the proximal and distal segments at the fracture site were determined $[17,20]$. The relative craniocaudal and lateromedial displacements ( $x$ and $y$ directions) and axial displacements ( $z$ direction) of the observed points were determined by the following relations:

$$
\begin{gathered}
r_{D(x)}=D_{p(x)}-D_{d(x)}, r_{D(y)}= \\
=D_{p(y)}-D_{d(y)}, r_{D(z)}=D_{p(z)}-D_{d(z)}
\end{gathered}
$$

where $r_{D(x)}, r_{D(y)}$ and $r_{D(z)}$ represent the relative displacements of the bone model segments at the fracture point in $x, y$ and $z$ directions, $D_{p(x)}, D_{p(y)}$ and $D_{p(z)}$ are the absolute displacements of the bone end points of the bone model proximal segments in the $x, y$ and $z$ directions, and $D_{d(x)}, D_{d(y)}$ 

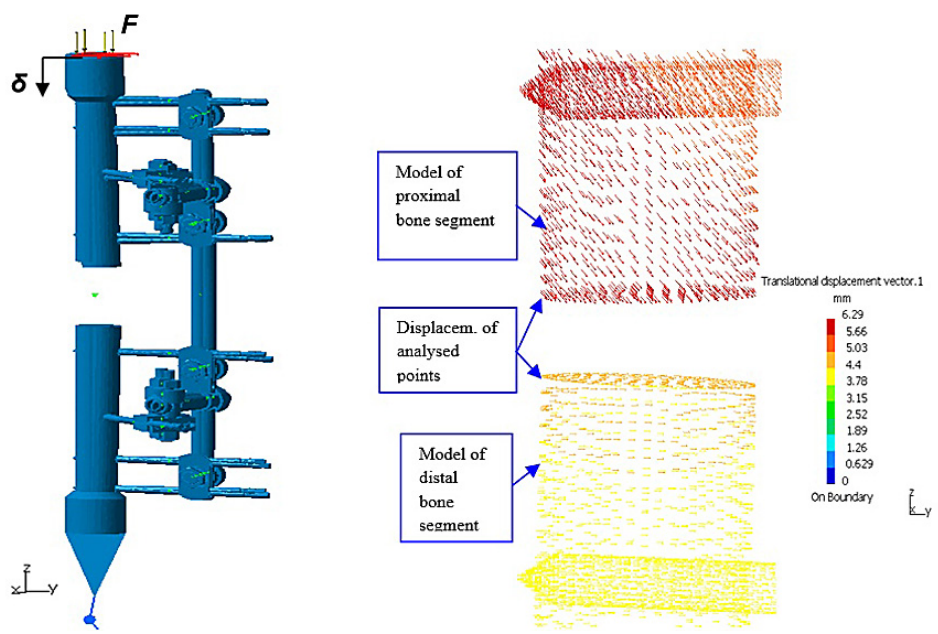

Fig. 2. Non-deformed and deformed structure under maximum axial load and interfragmentary movement at the fracture site

and $D_{d(z)}$ are the absolute displacements of bone end points of the bone model distal segments in the $x, y$ and $z$ directions.

The intensity of the maximum interfragmentary displacement vector at the fracture point $R$ is defined by:

$$
R=\sqrt{\left(r_{D(x)}\right)^{2}+\left(r_{D(y)}\right)^{2}+\left(r_{D(z)}\right)^{2}}
$$

Complete mechanical investigations of the fixator stability, in addition to the analysis of displacement at the fracture point, also include an analysis of principal stresses at the characteristic locations of the fixator structure $[12,16]$. Here, the stress analysis will be presented only for the case of axial loading by the compression force as the dominant load.

During the structural FEM and experimental analysis, the intensities and directions of the principal stresses $\sigma_{1}$ and $\sigma_{3}$ were monitored and analysed at two control points in the middle of the fixator tree [11]. The measurement point closer to the bone model segment is indicated by MP-, while the location on the opposite side of the tree is indicated by MP +, as shown in Figure 3 .

The experimental tests of the fixator were performed at a Material Testing Laboratory at Faculty of Mechanical Engineering of the University of Sarajevo using the tensometric analysis equipment. During these tests, the proximal bone segment movement was monitored by a displacement transducer, while the loading was controlled by a force transducer (type U2A by HBM - Hottinger Baldwin Messtechnik GmbH, Darmstadt, Germany) on a material testing machine (Zwick
GmbH \& Co., Ulm, Germany, model 143501). The stress analysis by tensometric measurements [6] was performed using a DMC 9012A digital measuring amplifier system with built-in DMV 55 modules to receive the signals from type 3/120LY11 strain gauges manufactured by HBM, as shown in Figure 4.

The comparative diagrams representing the change of principal stresses $\sigma_{1}$ and $\sigma_{3}$, as well as a comparative diagram of axial load as a function of displacement at the point of load obtained by experimental testing and FEM method are shown in Figure 5 and Figure 6. A good agreement of results is obtained with maximum deviations of $3.9 \%$ for displacements and $3.5 \%$ for principal stresses.

\section{Development of optimization model}

An iterative hybrid optimization algorithm was created, integrated into the $\mathrm{CAD} / \mathrm{CAM} / \mathrm{CAE}$ CATIA system, which operates at the combined global-local level [7, 8]. The algorithm globally uses the Simulated Annealing (SA) method, and locally Conjugate Gradient (CG) method.

In an explanation of the SA method functioning principle, the term temperature is used in conjunction with the Boltzmann criterion and represents a "mathematical temperature" of the optimization system [2]. The Boltzmann distribution considers the system energy $E$ at thermal equilibrium at temperature $T$ to be distributed by the following relation:

$$
P(E)=\mathrm{e}^{\left(-\frac{E}{k T}\right)}
$$

where: $P(E)$ is a probability of reaching the energy level $E$ and $k$ is Boltzmann constant. 

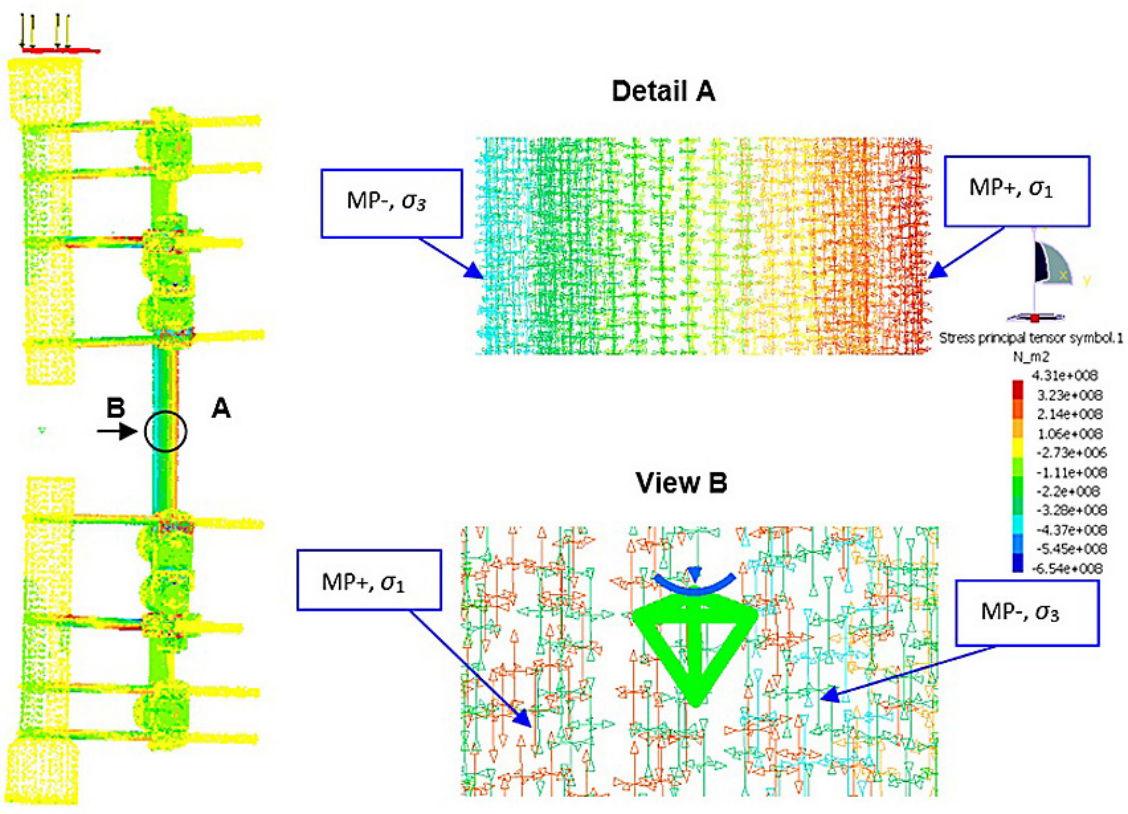

Fig. 3. Principal stresses

On the basis of the Metropolis criterion, the probability of accepting the following point (state) $\mathbf{x}_{i+1}$ depends on the difference in the energy levels or the values of the objective (cost) function of two analysed points (states):

$$
\begin{gathered}
\Delta E=E_{i+1}-E_{i}=\Delta f=f_{i+1}-f_{i} \equiv \\
\equiv f\left(\mathbf{x}_{i+1}\right)-f\left(\mathbf{x}_{i}\right)
\end{gathered}
$$

New energy state or new potential solution $\mathbf{x}_{i+1}$ is determined based on Boltzmann distribution:

$$
P\left[E_{i+1}\right]=\min \left\{\begin{array}{c}
\mathrm{e}^{\left(-\frac{\Delta E}{k T}\right)}, \Delta E>0 \\
1, \Delta E \leq 0
\end{array}\right.
$$

Solution space search begins with a global SA algorithm in order to avoid termination at a local optimum. After locating the approximate solution of global optimum, the CG based local search algorithm is activated determining the value of the global optimum.

Unlike the SA method, which is unconstrained by the shape of the constraint and objective functions, the CG method works with continuous differentiable functions [22]. The successive approximations for the minimum of the target function $f(\mathbf{x})$ in the CG method are generated using the iterative formula:

$$
\mathbf{x}^{(\mathrm{k}+1)}=\mathbf{x}^{(\mathrm{k})}+\alpha_{k} \mathbf{d}^{(\mathrm{k})}
$$

where: $\alpha_{k}$ is an optimal step size in the direction of $\mathrm{d}^{(\mathrm{k})}$ or a solution of 1D optimization problem:

$$
\min _{\alpha>0} f\left(\mathbf{x}^{(\mathrm{k})}+\alpha_{k} \mathbf{d}^{(\mathrm{k})}\right)
$$

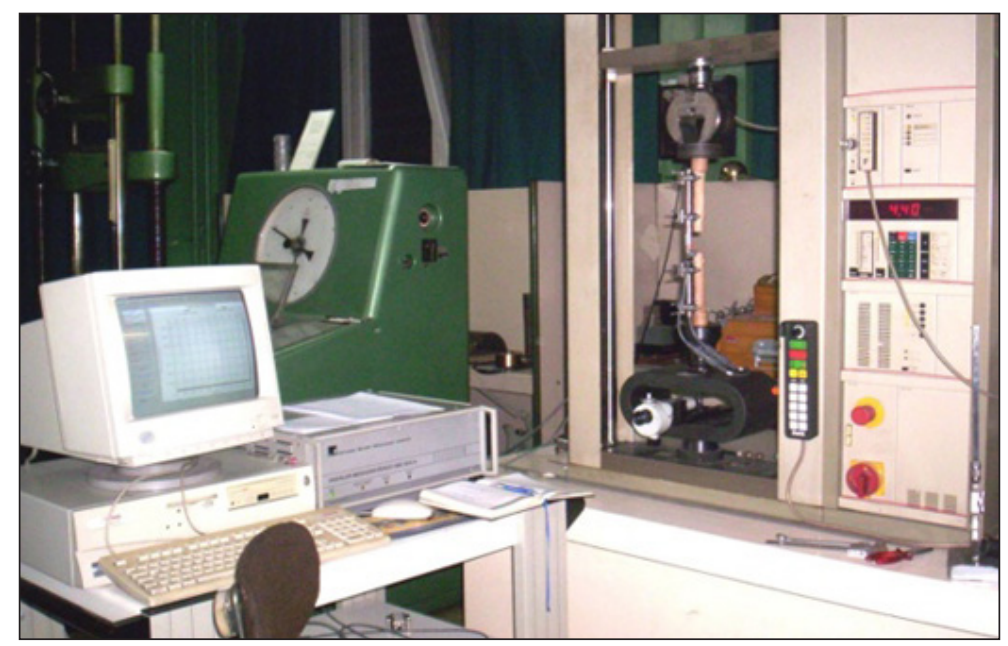

Figure 4. Experimental testing of the fixation device 


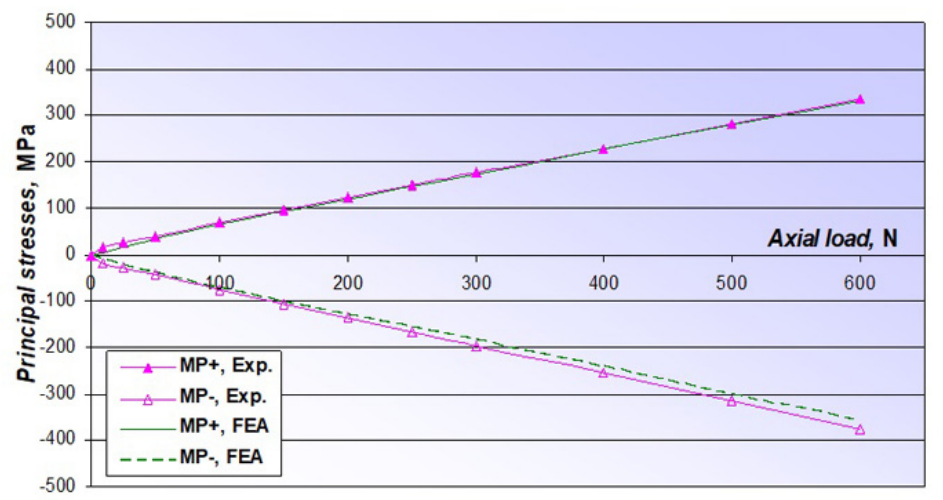

Fig. 5. Comparative diagram of the principal stresses ( $\sigma_{1}$ on MP +$)$ and ( $\sigma_{3}$ on MP- $)$

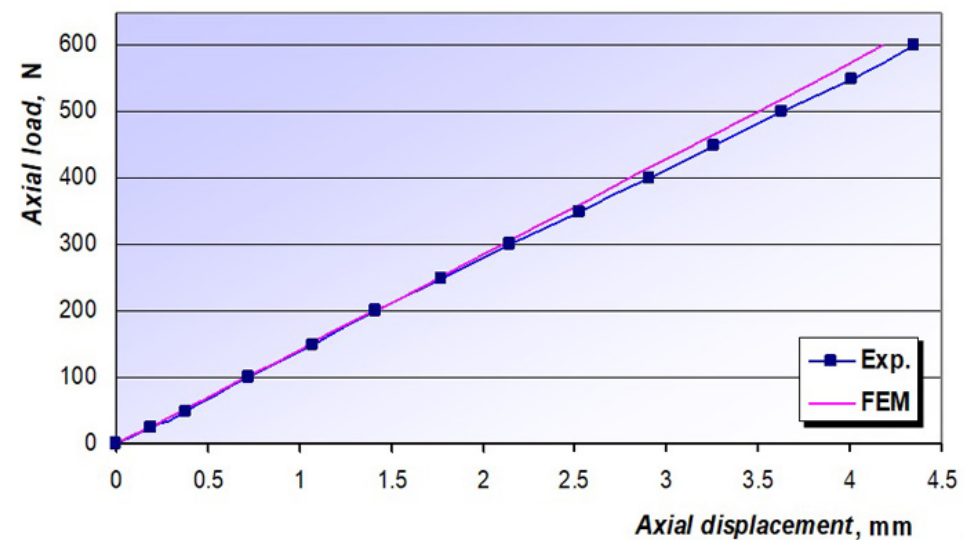

Fig. 6. Comparative diagram of the axial displacement at the point of load

Gradient of the objective function $f(\mathbf{x})=f\left(\mathrm{x}_{1}\right.$, $\left.\mathrm{x}_{2}, \ldots, \mathrm{x}_{\mathrm{n}}\right)$ represents a vector:

$$
\mathbf{c}=\nabla f(\mathbf{x})=\left[\frac{\partial f}{\partial x_{1}} \frac{\partial f}{\partial x_{2}} \cdots \frac{\partial f}{\partial x_{n}}\right]^{T}
$$

The negative gradient vector represents the direction of the steepest descent for the cost function and can be written as follows:

$$
\mathbf{d}=-\mathbf{c} \text { or } d_{i}=-c_{i}=-\frac{\partial f}{\partial x_{i}} i=1,2, \ldots, n
$$

The structural optimization performed achieved the size optimization of the external fixation device design components. The task of optimizing the fixator design is to minimize its volume while reducing the interfragmentary displacements at the point of fracture. During the optimization process, the Von Mises stresses on the structure components (optimisation constraints $g_{2}(\mathbf{x})$ and $g_{3}(\mathbf{x})$ ), were controlled so that their values were limited to the value of the allowable stresses. Additionally, it was necessary to control the interfragmentary displacements that were limited to clinically permissible displacements [20].
On the other hand, the values of design (optimization) parameters were limited in order to achieve the realistic design solutions and fulfil the optimization aims.

For a mobile structure such as an external fixator, reliable and expedited treatment (reduction of adverse displacements at the fracture point) with as little weight as possible, is imperative. For this reason, the minimum mass or volume of the fixator structure was selected for the cost function:

$$
\min f(\mathbf{x})=\min \sum_{i=1}^{n} A_{i} L_{i}
$$

where: $x=\left(\chi_{1}, \chi_{2}, \chi_{3}\right)$ is a vector of referent structural parameters used to parameterize the fixator model (Table 1), $n$ is the number of structural elements and $A_{i} L_{i}$ is the volume of $i$-th element of the fixator structure.

For the optimization variables (design parameters), the geometric parameters having a dominant influence on the research aim or the optimization process were selected. Specifically, the 
most influential parameters on the stability and mass of the fixator structure were determined by structural analysis and experimental testing [10] and they are outlined in Table 1. These parameters are called free parameters and can be assigned a range (lower and upper values) and a step. The assignment of boundary values to these free parameters is necessary in order to prevent unrealistic shapes and dimensions of the fixator design.

In this way, the area of the feasible structural solutions is directly affected. Since these are geometric parameters, thus the dimensional constraints are introduced into the optimization model. The dimensional constraints are defined as follows:

$x_{1 d} \leq x_{1} \leq x_{1 g} ; 12 \mathrm{~mm} \leq x_{1} \leq 20 \mathrm{~mm}$

$x_{2 d} \leq x_{2} \leq x_{2 g} ; 0.5 \mathrm{~mm} \leq x_{2} \leq 1.5 \mathrm{~mm}$

$x_{3 d} \leq x_{3} \leq x_{3 g} ; 1.5 \mathrm{~mm} \leq x_{3} \leq 3 \mathrm{~mm}$

The steps of the parameters defined at the initial phase of the optimization are actually the initial values that the algorithms in their work reduce in order to achieve convergence towards the optimal values of the parameters. If the search in certain direction is successful and the local optimum remains undiscovered, the step is increased in order to speed up the algorithm and determine the optimum.

\section{RESULTS AND CONCLUSIONS}

The results of the dimensional optimization of the Sarafix bone exterior fixation device are shown in diagrams in Figure 7 and Figure 8. Structural optimization sought to achieve its improvements in terms of reduced interfragmentary displacements and volume without major and complex structural interventions [8].

Thus, the fixator volume reduction from $1.143 \cdot 10^{5} \mathrm{~mm}^{3}$ to $1.032 \cdot 10^{5} \mathrm{~mm}^{3}$ was achieved. The optimal solution of the cost function (volume) was achieved in the $16^{\text {th }}$ iteration of the SA algorithm (Figure 7). Afterwards, the algorithm tried to further improve the value of the target function (from the $16^{\text {th }}$ to the $33^{\text {rd }}$ iteration). However, the optimization constraints become unsatisfied. After finding the solution by the global algorithm, the CG algorithm was activated, which resulted in an insignificant improvement of the target function value (from $1.036 \cdot 10^{5} \mathrm{~mm}^{3}$ to $1.032 \cdot 10^{5} \mathrm{~mm}^{3}$ ), as presented in Figure 7 .

The referent design parameters underwent certain changes. Thus, in order to optimize the fixator design, the diameter of the tree $d_{s}$ was increased, while at the same time the wall thicknesses of the fixator tree $\delta$ and the clamping plate $\delta_{o p}$ were decreased, as shown in Figure 8 and Table 2.

Table 1. Optimization variables (referent construction parameters) of the fixation device model

\begin{tabular}{|l|c|c|c|c|}
\hline \multicolumn{1}{|c|}{ Parameter } & \multicolumn{2}{|c|}{ Index } & Perimeter, $\mathrm{mm}$ & Step, $\mathrm{mm}$ \\
\hline Outer tree diameter & $x_{1}$ & $d_{s}$ & $12 \div 20$ & 0.5 \\
\hline Tree wall thickness & $x_{2}$ & $\delta$ & $0.5 \div 1.5$ & 0.1 \\
\hline Clamping plate base thickness & $x_{3}$ & $\delta_{p o}$ & $1.5 \div 3$ & 0.2 \\
\hline
\end{tabular}

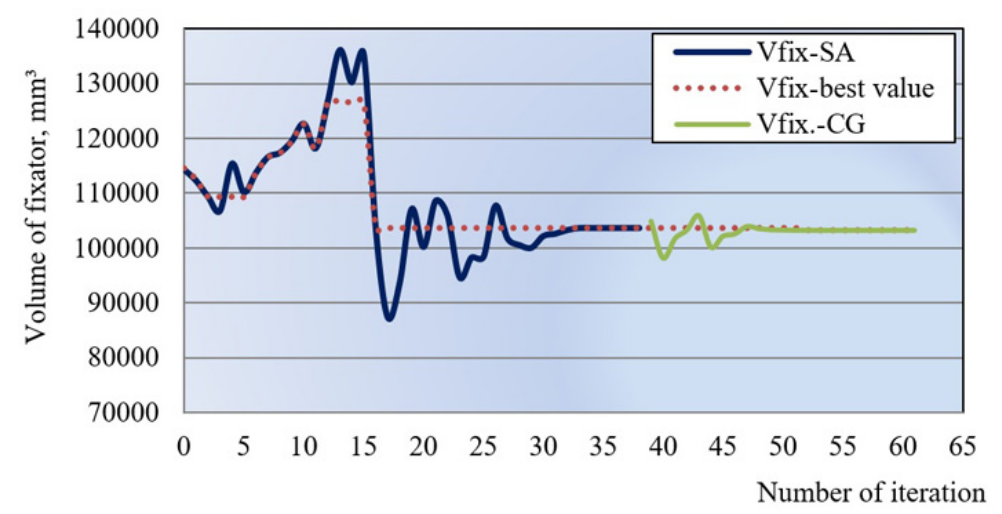

Fig. 7. Fixation device volume optimisation 


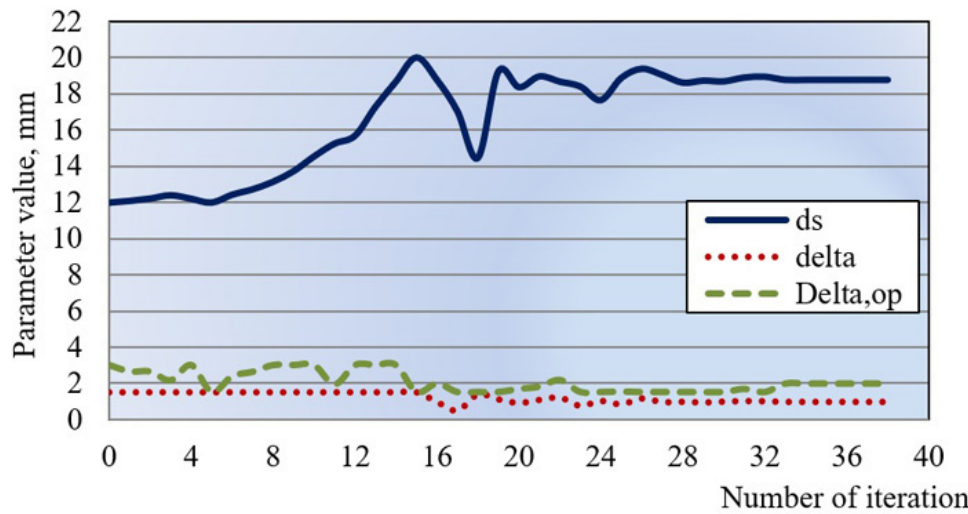

Fig. 8. Change of optimisation parameters

Table 2. Comparison between current and optimized fixation device design characteristics

\begin{tabular}{|l|c|c|c|c|}
\hline \multicolumn{1}{|c|}{ Characteristics / parameter } & Index & Unit of measure & Current design & Optimized design \\
\hline Volume & $f(\mathbf{x}), V$ & $\mathrm{~mm}^{3}$ & $1.143 \cdot 10^{5}$ & $1.032 \cdot 10^{5}$ \\
\hline Outer tree diameter & $x_{1}, d_{s}$ & $\mathrm{~mm}$ & 12.000 & 18.764 \\
\hline Tree wall thickness & $x_{2}, \delta$ & $\mathrm{mm}$ & 1.500 & 0.974 \\
\hline Clamping plate thickness & $x_{3}, \delta_{o p}$ & $\mathrm{~mm}$ & 3.000 & 1.965 \\
\hline $\begin{array}{l}\text { Von Mises stress at control point MP- } \\
\text { (compression) }\end{array}$ & $g_{2}(\mathbf{x}), \sigma_{v m-}$ & $\mathrm{MPa}$ & 354.3 & 183.5 \\
\hline $\begin{array}{l}\text { Von Mises stress at control point MP+ } \\
\text { (tension) }\end{array}$ & $\sigma_{v m+}$ & $\mathrm{MPa}$ & 330.0 & 162.0 \\
\hline Von Mises stress at clamping plate & $g_{3}(\mathbf{x}), \sigma_{v m, p}$ & $\mathrm{MPa}$ & 450.0 & 517.8 \\
\hline \multirow{2}{*}{$\begin{array}{l}\text { Proximal bone segment displacement vector } \\
\text { components at fracture point }\end{array}$} & $D_{p(x)}$ & $\mathrm{mm}$ & 0.530 & 0.327 \\
\cline { 2 - 5 } & $D_{p(y)}$ & $\mathrm{mm}$ & 4.140 & 1.150 \\
\hline \multirow{2}{*}{$\begin{array}{l}\text { Proximal bone segment maximum resultant } \\
\text { displacement }\end{array}$} & $D_{p(z)}$ & $\mathrm{mm}$ & -4.360 & -1.500 \\
\hline \multirow{2}{*}{$\begin{array}{l}\text { Distal bone segment displacement vector } \\
\text { components at fracture point }\end{array}$} & $g_{1}(\mathbf{x}), D_{p}$ & $\mathrm{~mm}$ & 6.280 & 1.990 \\
\cline { 2 - 5 } & $D_{d(x)}$ & $\mathrm{mm}$ & 0.530 & 0.327 \\
\hline $\begin{array}{l}\text { Maximum interfragmentary displacement at } \\
\text { fracture point }\end{array}$ & $D_{d(y)}$ & $\mathrm{mm}$ & 4.290 & 1.160 \\
\hline
\end{tabular}

The process of structural optimization sought to reduce the volume of certain components by affecting the total volume $V$ of the fixator while improving its mechanical characteristics, as shown in Table 2. The major improvements are reflected in the reduction of the interfragmentary displacements at the bone fracture point $D p_{(\mathrm{i})}$ and $D d_{(\mathrm{i})}$.

It is important to mention that the structural optimization process achieved a structural solution of the fixator, which allows significantly smaller transverse displacements at the fracture point $D_{p(y)}$ and $D_{d(y)}$, compared to the current structure (Table 2). It is known that these transverse displacements can slow or prevent the healing of the fracture and cause pseudoarthrosis.

\section{Acknowledgements}

The authors gratefully acknowledge the support of Federal Ministry of Education and Science of Federation of Bosnia and Herzegovina.

\section{REFERENCES}

1. Amirouche F. Principles of Computer-Aided Design and Manufacturing. 2nd edition, Prentice Hall, Upper Saddle River, New Jersey, 2004.

2. Arora J.S. Introduction to Optimum Design, Academic Press, 2nd Edition, 2004.

3. Fancello E.A., Haslinger J. and Feijóo R.A. Numerical comparison between two cost functions in contact shape optimization. Structural Optimization, 9(1), 1995, 57-68. 
4. Fancello E.A. Topology optimization for minimum mass design considering local failure constraints and contact boundary conditions. Structural and Multidisciplinary Optimization, 32(3), 2006, 229-240.

5. Hilding D., Klarbing A. and Petersson J. Optimization of structures in unilateral contact. Applied Mechanics Reviews, 52(4), 1999, 139-160.

6. Khan A.S. and Wang X. Strain Measurements and Stress Analysis, Prentice-Hall, New Jersey, USA, 2001.

7. Konig O. and Wintermantel M. CAD-based Evolutionary Design Optimization with CATIA V5, Weimarer Optimierungs- und Stochastiktage 1.0, 2004.

8. Mešić E. Development of an integrated CAD/KBE system for design/redesign of external bone fixation devices, $\mathrm{PhD}$ thesis, Mechanical Engineering Faculty Sarajevo, 2013.

9. Mešić E., Avdić V., Pervan N. and Repčić N. Finite element analysis and experimental testing of stiffness of the Sarafix external fixator. Procedia Engineering, 100, 2015, 1598-1607.

10. Mešić E., Pervan N., Repčić N. and Muminović A. Research of influential constructional parameters on the stability of the fixator Sarafix. Annals of DAAAM for 2012 \& Proceedings of the 23rd International DAAAM Symposium Intelligent Manufacturing \& Automation: Focus on Sustainability, Editor: Katalinic B., Zadar, Croatia, October 24th27th, 2012, 561-564.

11. Mešić E., Avdić V. and Pervan N. Numerical and experimental stress analysis of an external fixation system. Folia Medica Facultatis Medicinae Universitatis Saraeviensis, 50(1), 2015, 74-80.

12. Mešić E., Muminovic J.A. and Repčić N. Geometrical modelling and structural analysis of the Sarafix fixator configurations. Annals of DAAAM for 2012 \& Proceedings of the 23rd International DAAAM Symposium Intelligent Manufacturing \& Automation: Focus on Sustainability, Editor: Katalinic B., Zadar, Croatia, October 24th-27th, 2012, 69-74.

13. Mesic E., Muminovic A., Delic M., Čolić M. and Pervan N. Topological Optimization and Finite Element Method Analysis of Wheels on the Carts Winch Bridge Crane. TEM Journal, 8(4), 2019, 1288-1294.

14. Muminovic A.J., Muminovic A., Mesic E., Saric I. and Pervan N. Spur Gear Tooth Topology Optimi- zation: Finding Optimal Shell Thickness for Spur Gear Tooth produced using Additive Manufacturing. TEM Journal, 8(3), 2019, 788-794.

15. Pervan N., Mešić E. and Čolić M. Stress analysis of external fixator based on stainless steel and composite material. International Journal of Mechanical Engineering \& Technology, 8(1), 2017, 189-199.

16. Pervan N., Mešić E., Čolić M. and Avdić V. Stiffness Analysis of the Sarafix External Fixator of Composite Materials. International Journal of Engineering \& Technology, 5(1), 2016, 20-26.

17. Pervan N., Mešić E., Čolić M. and Avdić V. Stiffness Analysis of the Sarafix External Fixator based on Stainless Steel and Composite Material. TEM Journal, 4(4), 2015, 366-372.

18. Pervan N., Muminović A.J., Muminović A. and Delić, M. Development of Parametric CAD Model and Structural Analysis of the Car Jack. Advances in Science and Technology Research Journal, 13(3), 2019, 24-30.

19. Pervan N., Čolić M., Šarić I. and Hadžiabdić V. Analysis of the Haulage Ropes on Ropeways in Case of Accidental Loads. TEM Journal, 5(2), 2016, 171-174.

20. Radke H., Aron D.N., Applewhite A. and Zhang G. Biomechanical Analysis of Unilateral External Skeletal Fixators Combined with IM-Pin and without IM-Pin Using Finite-Element Method, Veterinary Surgery 35, 2006, pp. 15-23.

21. Saric I., Pervan N., Muminovic A. and Colic M. Development of Integrated Intelligent Cad System for Design of Shafts. Tehnički vjesnik, 25(Supplement 1), 2018, 99-104.

22. Spillers W.R. and MacBain K.M. Structural Optimization. Springer, 2009.

23. Swantner A. and Campbell M.I. Topological and parametric optimization of gear trains. Engineering Optimization, 44(11), 2012, 1351-1368.

24. Wu J., Clausen A. and Sigmund O. Minimum compliance topology optimization of shell-infill composites for additive manufacturing. Computer Methods in Applied Mechanics and Engineering, 326, 2017, 358-375.

25. Zienkiewicz O.C., Taylor R.L. and Zhu J.Z. The Finite Element Method: Its Basis and Fundamentals. 6th edition, Butterworth-Heinemann, Oxford, 2005. 